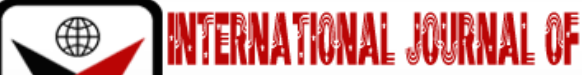

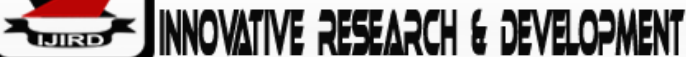

ISSN 2278-0211 (Online)

\section{The Readiness of the Ghanaian Fashion Industry forthe Absorption of Industry 4.0}

\author{
Jacqueline Ogoe \\ Lecturer, Department of Clothing and Textiles Education, \\ University of Education, Winneba, Ghana \\ Richard Acquaye \\ Senior Lecturer, Department of Textile Design and Technology, \\ Takoradi Technical University, Takoradi, Ghana
}

\begin{abstract}
:
This paper reviewed issues pending current trend in the fashion industry while assessing the readiness of fashion institutions in Ghana for the absorption of industrial revolution popularly referred to as industry 4.0. With the invention of new technologies the fashion industry has improved significantly over the years. However, the role of the fashion industry in the achievement of Industry 4.0 in most developing countries seem to be challenged by several factors which ultimately impacts on the ability of the industry to effectively incorporate features of Industry 4.0 demands in its activities. With the focus on Ghana, the fashion industry is seemingly open to embrace new technologies in its production processes but lacks mainly the technical know-how and the industry specific accouterments needed to make the real changeover into Industry.
\end{abstract}

Keywords: fashion, fashion industry, industry 4.0, industrial revolution, smart clothing

\section{Introduction}

Global transformation is gradually altering the way man lives, work and relate with one another. Chou et al. (2018) indicated that the current industrial revolution popularly termed "industry 4.0" is characterized by a fusion of technology that is blurring the lines between the physical, digital and biological spheres. The introduction of smart factories and smart fashion in the era of Industry 4.0 is marked by extensive digitalization and automation with the application of Information Technologies (IT) and electronic devices in services and manufacturing within the fashion industry (Ahmed et al., 2018). This transformation has created a shift in current industrial activities and human thinking (Kurniawanet al., 2019). Thus, making it easier for industries to collaborate and share data among customers, manufacturers, suppliers and other related parties in the supply chain.

The first industrial revolution or Industry 1.0 (I 1.0) is characterized by mechanized production processed using water and steam power. Mass production served as the striking feature of the first industrial revolution. Industry 2.0 (I 2.0) came about with the advent of electricity while Industry 3.0 (I 3.0) welcomed the age of electronics and information technology. The second industrial revolution was characterized by improved production standards and speed while in the third industrial revolution, the use of the internet and computer aided applications was adopted in manufacturing (Hermann et al., 2016; Wang et al., 2018).

The present age of Industry 4.0 (I 4.0) is characterized by advancement in technologies. These include the introduction of technologies such as artificial intelligence, cloud computing, cyber-physical systems, emphasizing digitization, and the internet of things (Hermann et al., 2016; Wang et al., 2018). According to Chen (2014), I 4.0 was born from the idea of connecting physical equipment or factories with digital data that leads to intelligent manufacturing. I4.0 is basically characterized by concepts such as automation, digitalization, and artificial intelligence are altering production processes (Madsen, 2019). The fourth industrial revolution is denoted as 'Industrial Internet of Things (IIoT)' in the United States and as 'Industry 4.0' in Germany (Bertola \& Teunissen, 2018). Industry 4.0 has also over the years been referred to as 'smart manufacturing', 'integrated internet' and 'industrial internet' (Hofmann and Rüsch, 2017).

Industrial transformation has been a major global topic for discussion in recent times (Petrillo et al. 2018). Kurniawan and Kundurpi (2019) found that the transformation has created a shift in current industrial activities and human thinking. The goal is to enable autonomous decision-making process in real time and enable real time connected value creation networks through early involvement of stakeholders. Thus, making it easier for industries to collaborate and share data among customers, manufacturers, suppliers and parties in the supply chain. The fashion industry is one of the key sectors that has been influenced by this transformation. With the invention of new smart machineries, tools and equipment, production within the fashion industry has improved significantly. 
A study by Hoque and Rasiah (2021) pointed a gap in literature relating to technology, organization, environment and institutional theories for the adoption of technology. Early studies by Petrillo (2018) placed much emphasis on use of knowledge as crucial to smart learning and technology adoption. Behr (2018) explained this by demonstrating how technology, innovation and communication offer enabling opportunities for new product development. A critical analysis of digital transformation provides insights into varying opportunities in the product manufacturing, supply and consumption (Kurniawan, 2020).

Several studies have indicated that the concept of I 4.0 is implemented in several sections of the fashion industry such as forecasting, consumer research, design, product development, merchandising, sourcing, manufacturing, and retailing/distribution (Brodtmann, 2016; Ha-Brookshire \& Hawley, 2013; Lasiet al., 2014). With the help of computer aided applications, the fashion designer can edit, modify or redraw sketches or swatch. This offers the designer the opportunity of envisioning the various possibilities that can be adopted in less time than if the manual approach had been adopted (Aboagye, 2009; Yaw, 2013). Examples of computer aided software that can be used in the fashion industry include CorelDraw, Adobe Illustrator, Adobe Photoshop, and Digital Fashion Pro. The help of these software packages are enlisted in creating patterns or designs, cutting or creating an illustration.

Additionally, the advent of I 4.0 has also birthed smart clothing (clothing that is equipped with technological and digital features), smart watches and glasses and other forms of intelligent apparels (Behr, 2018). Some global fashion companies have incorporated I 4.0 or the 'smart factory phenomenon' into their production activities by utilizing laser cutting, linear digital printing or 3D printing technologies in their manufacturing process (Bertola \& Teunissen, 2018). For instance, brands like Adidas and Nike implemented electronic knitting processes in producing its knitted sneakers since 2012(Bertola \& Teunissen, 2018).

Furthermore, digitalization has enabled fashion consumers to look through several options, compare prices, shop for items and have those items delivered at their doorsteps without having to step outside (Hagelberg, 2017). Similarly, the dawn of Industry 4.0 has brought markets closer to consumers through the use of social media thus allowing companies to advertise their wares online with ease. According to Behr (2018), the fashion industry will undergo more changes as a result of more companies incorporating digital processes into production activities. Hence, a critical review on the readiness of fashion institutions in Ghana for the absorption of industry 4.0 is deemed necessary.

\section{Literature Review}

\subsection{Skill Requirements for a Digitalized Fashion Industry}

In the fashion industry, transition from I 3.0 (mass production and retailing) to I 4.0, which relies a lot on digital interactions in the fashion industry, could serve as a challenge to contexts that have a low grasp on technological advancements or digital resources (Hermann et al., 2016). Industry 4.0 represents a dawn of an era where technological aptness is the order of the day, thus in sectors or industries that rely on technological systems will have several low-skilled individuals being redundant (Wang et al., 2018).

Petrillo et al (2018) perceived an increase in digital workers against manual workers. Thus, bridging the gap between traditional working approach and a transformed digital working environment as shared earlier by HirschKreinsen and Weyer (2014).Wang et al. (2018) concluded in his study that forecasting, consumer research, and design are the key areas that require high digital proficiency in employees in the fashion sector. Employees are expected to command a mastery of these foremost stages of a fashion business process. Adding on, Petrillo et al. (2018) emphasized on digital skills as prerequisite for the implementation of industrial revolution in order to fully transform the industry. Emphasizing on the future workforce, Karacay (2018) stressed on the need to identify new talents and re-skilling existing labour. Hence, new educational models geared towards industrial transformation is required to effectively transition towards becoming a digitalized industry. The level to which industries are able to exploit and benefit from industry 4.0 is influenced by its implementation of strategies (Stentoft et al. 2019). Petrillo et al (2018) noted three (3) key steps to support the adoption and implementation of industrial transformation: awareness creation; innovative management education and identification of potential improvements of systems.

\subsection{Opportunities Available in a Digitalized Fashion Industry}

Berman (2012) explained the strategies businesses need to employ by adopting new business models to meet consumer needs. This is crucial to meeting customer interaction thus, leading to innovation. A critical analysis of digital transformation provides insights into varying opportunities in the product manufacturing, supply and consumption (Kurniawan, 2020). Bertola and Teunissen (2018) indicated how industrial transformation ideas have been left unexplored as expected but believed there were trajectories that the both the textile and fashion industry can effectively cease. Behr (2018) concluded by demonstrating how technology, innovation and communication offer enabling opportunities for new product development.

The role of the fashion industry in the achievement of industry 4.0 in most developing countries seem to be challenged by several factors relating to human resource, financial resource and effective industrial system support. Bertola and Teunissen (2018) indicated how industrial transformation ideas have been left unexplored as expected but believed there were trajectories that the both the textile and fashion industry can effectively cease. Similarly, there seem to be literature relating to technology-organization-environment and institutional theories for the adoption of technology (Hoque\&Rasiah, 2021). Hence, new educational models geared towards industrial transformation is required to effectively enroll a digitalized industry and economy. Digitalization in all sectors seem imperative for all economies yet not much seem to be realized in our institutions that usually train graduates to fill industrial gap. These and among other perceived 
factors, informed this study to look into how institutions in Ghana are preparing towards meeting the demands of the industry 4.0 concepts in order to determine the fashion institutions' readiness to absorb and implement digitalization.

\subsection{Factors Influencing the Ability of the Ghanaian Fashion Industry Absorbing Industry}

\subsubsection{Low Level of Modernized Training in Fashion-Oriented Concepts}

Most fashion/garment production industries rely on traditional methods for production and training. Currently, Ghana may not have enough requisite trained professionals to support the development and deployment of Industry 4.0 initiatives in Ghana. There are few lecturers with specializations in certain fashion-oriented courses such as Pattern Technology, Fashion Drawing and Illustration, and Garment Technology. Thus, the effectiveness of tutorship in such courses will be minimal (Sarpong et al., 2012). Thus, graduates may not be able to fit into current industrial demands therefore, requiring the industries to retrain candidates to fit their needed demands.

According to the findings of a study by Sarpong et al., (2012), indicated that due to the practical nature of fashion oriented courses, a more inclusive approach of pedagogy where students are engaged in discussions and practical lessons is more effective. The practical lessons will equip students with the technical know-how needed in their professional lives. Government interventions at various educational levels through updating curricula into modernized and more practical ones will also mark a turn in the fortunes of the fashion industry.

\subsubsection{Lack of Requisite Equipment for Production}

Sarpong and Howard (2011) noted lack of capital, knowledge and vital skills, as well as low and irregular income as the challenges that prevent some fashion players from embracing the components of Industry 4.0 into their fashion activities.Additionally, most fashion training institutions seem ill-equipped with modern machineries and techniques for production.Tools and equipment used by garment and textile producers are mostly out of date. This affects production process and resource use. Adding on, Yaw(2013) described fashion designers who stick to traditional ways of sketching their ideas, plagued with a chunk of work. Yaw (2013) further indicated that new technological software should be incorporated into the fashion industry to facilitate its activities.

\subsubsection{The Impact of Social Media and Other Technological Platforms}

Varying forms of knowledge can be obtained from the use of social media and other platforms such as client taste and preferences, supplier information, fashion trends, orders from customers, current prices, comments, critiques and recommendations of clients. Moreover, fashion designers utilize social media channels to market their designs as well as to obtain knowledge to make new designs (Owusu-Bempah, 2016). Well-known fashion designers in Ghana include MKOGH, Woodin, PKOG, and ElikemKumordji(Owusu-Bempah, 2016). According to Owusu-Bempah (2016), fashion designers in Ghana to some extent utilize several social media applications such as Facebook, YouTube, Pinterest, Twitter, Google Plus and Instagram. He further noted that these applications were used on a day to day basis to acquire information, checkout new trends and styles, and interact with a broad audience that includes clients, suppliers and other fashion designers (Owusu-Bempah, 2016). This situation is however not so dominant in developing countries. The full advantages of social media in daily business activities is not fully exploited in developing nations like Ghana (Owusu-Bempah, 2016).

On the global scale, top fashion brands like Gucci have incorporated the use of social media into their business activities (thereby not relying on just its website), as they regularly advertise their crafts on platforms like Facebook and Twitter (Kim \&Ko, 2012). According to Owusu-Bempah (2016), there are 127 fashion firms in Ghana per reports found in the Ghana Business Directory. Out of this number, a large number (87) of them (representing 68.5 percent) do not exploit the use of social media in their business activities. A stark contrast of 40 firms (representing about 31.5 percent) on the other hand utilized social media in their business activities (Owusu-Bempah, 2016). There is however a gradual improvement in the number of Ghanaian fashion companies who are embracing the use of social media (Asiedu, 2017).

\subsubsection{Minimal Use of Computer Aided Applications in Production Processes}

The impact of technology on the fashion industry is evident with the influx of computer aided applications which prove to be vital in designing (Yaw, 2013). Per the advantages that can be derived from embracing the use of digital designs, several players in the global fashion industry are adopting the use of computer software for designing. In Ghana, the use of software that aid in designing in the fashion industry has been barely exploited (Yaw, 2013). This stems from the fact that some fashion trainees and instructors get confused with CAD systems and consequently become disenchanted with the technology (Yaw, 2013). Yaw (2013) advised on the need for institutions to give critical attention to the adoption and use of computer aided applications as a pedagogy tool in fashion design curricula. Furthermore, the researcher recommended that a conscious attempt be made by the fashion industry players to organize periodic seminars and workshops to attune members with emerging software packages as well as organize competitions involving the use of these software (Yaw, 2013).

\subsubsection{The Influence of Foreign Competition}

A study by Sarpong \& Howard (2011) on the effect of globalization on the fashion scope in the Ghanaian terrain portended that the fashion space in the country is bedeviled with used and cheap clothing from other parts of the world. Sarpong \& Howard (2011)added that the implementation of strategies such as limiting the influx of foreign wares into the Ghanaian market by the government will go a long way into boosting confidence in and increasing patronage of locally made products. Furthermore the availability and accessibility of governmental support (in the form of loans) to members 
of the fashion industry will help in procuring more modernized and effective tools, equipment and raw materials that will enhance production processes (Sarpong \& Howard, 2011).

\subsubsection{Low Performance of Local Wares on International Markets}

Several developing nations like Ghana are also failing to rake in fiscal returns on the international fashion market due to a lack of growth of her local fashion industry (Amankwah et al., 2012). Ghana generates low income from the exportation of fashion products (Sarpong \& Howard, 2011). This may be due to a split of market shares with other African countries and poor standards of products. Several Ghanaians are stagnant in their ways and pride themselves in sticking to traditionally styled apparels (Shepard, 2014). Unfortunately, some of these styles are no longer competitive on the global scale. For most of these individuals, these clothes retain a symbolic or cultural significance. Some Ghanaians are however gradually infusing some western styles into their cherished traditional clothing (Amankwah et al., 2012). Low performance on global markets discourages fashion companies from investing in modernized ways of production.

\section{Conclusion}

In assessing Ghana's readiness to absorb the concept of digitalization, it appears not much of such industrial movement is realized in most institutions and companies in Ghana. Generally, the fashion industry in Ghana is seemingly open to embrace new technologies in its production processes but lacks mainly the technical know-how and the industry specific accouterment needed to make the real changeover into Industry 4.0. Governmental policies geared towards fostering a vibrant and sustainable fashion industry will also churn out economic benefits to individual companies and the nation as a whole (Amankwah et al., 2012). Therefore, it is believed when the Ghanaian industries and institutions are given the requisite infrastructure and training, they can effectively adopt this system to save the future.

\section{References}

i. Aboagye, I. (2009). Ideation of selected natural objects for textile design using the computer.Unpublished thesis, KNUST.

ii. Ahmad, N., Shamsuddin, A. \&Aslinda, A.S. (2018). Industry 4.0 implications on human capital:

iii. A Review. J. Stud. Manage. Plan, 4, 220-235.

iv. Amankwah, A. M., Howard, E. K., \&Sarpong, G. D. (2012). Foreign fashion influence on the Ghanaian youth and its impact on the local fashion industry. International Journal Innovative Research \& Development, 1(11), 562-575.

v. Asiedu, F. O. (2017). Social media advertising and consumer decision-making in the fashion industry. Master of Philosophy Thesis, University of Ghana, 1-143.

vi. Behr, O. (2018). Fashion 4.0 - Digital Innovation in the Fashion Industry. Journal of technology and innovation management, 2(1), 1-9.

vii. Berman, S. J. (2012). Digital transformation: opportunities to create new business models. Strategy \& Leadership.

viii. Bertola, P., \&Teunissen, J. (2018). Fashion 4.0. Innovating fashion industry through digital transformation. Research Journal of Textile and Apparel, 22(4), 352-369. https://doi.org/10.1108/RJTA-03-2018-0023

ix. Brodtmann, T. (2016). Why Industry 4.0 is not just about industry. Retrieved fromhttps://www.euractiv.com/ section/digital/opinion.

x. Chen, Z. W. (2014). Industry 4.0 in Germany. World Science, 5, 6-13.

xi. Chou, C. M., Shen, C. H., Hsiao, H. C. \& Shen, T. C. (2018). Industry 4.0 manpower and its teaching connotation in technical and vocational education: Adjust 107 Curriculum Reform. International Journal of Psychology and Educational Studies, 2018, 5 (1), 9-14

xii. Gökalp, E., Gökalp, M. O., \&Eren, P. E. (2018). Industry 4.0 revolution in clothing and apparel factories: apparel 4.0. Industry 4.0 From the Management Information Systems Perspectives, 169-184.

xiii. Ha-Brookshire, J. E., \& Hawley, J. M. (2013). Envisioning the clothing and textile-relateddiscipline for the 21st century its scientific nature and domain from the global supply chain perspective. Clothing and Textiles Research Journal, 31(1), 17-31.

xiv. Hagelberg, L. (2017). Consumers' attitudes towards fashion and the effect of digitalization on their fashion consumption. Masters Thesis, University of Oulu, 1-95.

xv. Hermann, M., Pentek, T., \& Otto, B. (2016). Design principles for Industry 4.0 scenarios.Paper presented at the 49th Hawaii International Conference on System Sciences, Koloa, HI.

xvi. Hirsch-Kreinsen, H., \&Weyer, J. (2014). Change of production work-"Industry 4.0 ".

xvii. Sociological Working Paper 38. Dortmund: Technische Universität Dortmund.

xviii. Hofmann, E., \& Marco, R. (2017). Industry 4.0 and the current status as well as futureprospects on logistics. Computers in Industry, 89: 23-34.

xix. Hoque, M. A., Rasiah, R., Furuoka, F., \& Kumar, S. (2021). Technology adoption in the apparel industry: insight from literature review and research directions. Research Journal of Textile and Apparel.

xx. Karacay, G. (2018). Talent development for Industry 4.0. In Industry 4.0: Managing the digital transformation.Springer, Cham, 123-136.

xxi. Kim, A. J., \&Ko, E. (2012). Do social media marketing activities enhance customer equity? Anempirical study of luxury fashion brand. Journal of Business Research, 65(10), 1480-1486.

xxii. Kurniawan, J. H., \&Kundurpi, A. (2019). Integrating human geography into futures studies: Reconstructing and reimagining the future of space. Geography Compass, 13(6), e12443. 
xxiii. Kurniawan, F. E. (2020). Industrial Relations in the Digital Sharing Economy: A Critical Review of Labor Informalization and Social Partnership Relations. Journal of Indonesian Social Sciences and Humanities, 10(1), 47-57.

xxiv. Lasi, H., Kemper, H. G., Fettke, P., Feld, T., \& Hoffmann, M. (2014). Industry 4.0. Business \&Information Systems Engineering, 6(4), 239-242.

xxv. Lee, J., Bagheri, B., \& Kao, H. A. (2015). Cyber-physical systems architecture for industry 4.0-based manufacturing systems. Manufacturing letters, 3, 18-23.

xxvi. Leung, R. (2013). Increasing Dynamic Capabilities of Health Organizations with Social Media.

xxvii. Social Media in Strategic Management, ISSN: 1876- 0562.

xxviii. Madsen, D. Ø. (2019). The emergence and rise of industry 4 . 0 viewed through the lens of management fashion theory. MDPI Administrative Sciences, 9(71), 1-25.

xxix. Optitex. (2017). Digital product solutions. Retrieved from http://optitex.com/

xxx. Owusu-bempah, E. (2016). An absorptive capacity perspective of organizational learning through social media: evidence from the Ghanaian fashion industry. Master of Philosophy Thesis, University of Ghana, 10243534, 1215.

xxxi. Petrillo, A., De Felice, F., Cioffi, R., \&Zomparelli, F. (2018). Fourth industrial revolution: Current practices, challenges, and opportunities. Digital transformation in smart manufacturing, 1-20.

xxxii. Sarpong, G. D., \& Howard, E. K. (2011). Globalization of the fashion industry and its effects on Ghanaian independent fashion designers. 31(3), 97-106.

xxxiii. Sarpong, G. D., Howard, E. K., \&Amankwah, A. (2012). Teaching of fashion and textiles studies in Ghanaian tertiary institutions. International Journal of Innovative Research and Development, 1(9), 472-485.

xxxiv. Shepard, C. (2014). Vagabond Journey.Retrieved from www.vagabondjourney.com.

xxxv. Wang, B., Ha-brookshire, J. E., \& Ha-brookshire, J. E. (2018). Exploration of Digital competency requirements within the fashion supply chain with an anticipation of industry 4. 0. International Journal of Fashion Design, Technology and Education, 1754-3274. https://doi.org/10.1080/17543266.2018.1448459

xxxvi. Yaw, E. A. (2013). Developing digital techniques for fashion illustration. Masters of Arts Thesis, KNUST, 1-86. 